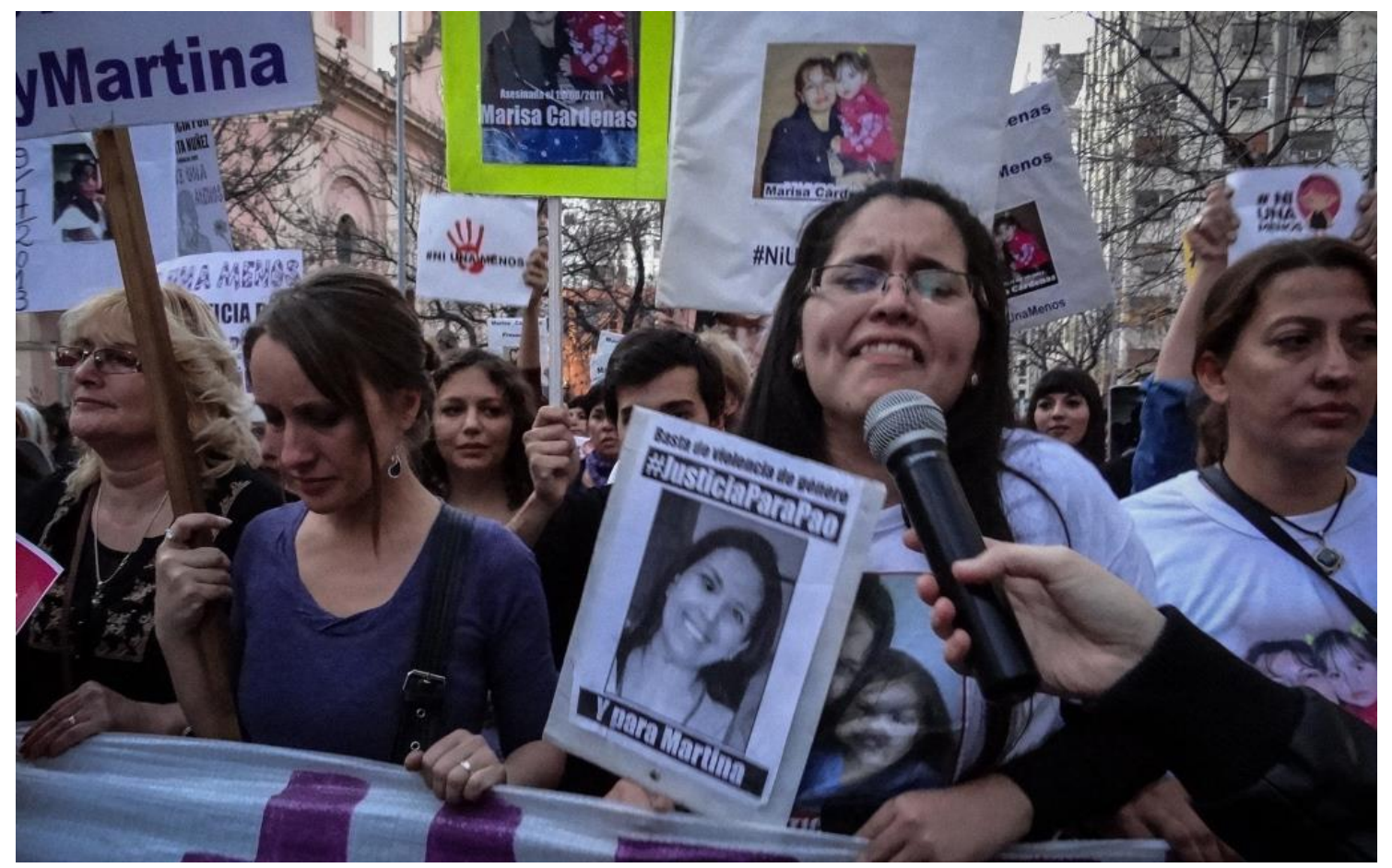

FOTOS: Irina Morán - Revista Alfilo - Periodista Feminista. Militante de Ni Una Menos Córdoba y Mujeres por un parto Respetado 


\title{
AMAZONAS: mulheres e formação docente no PARFOR
}

\begin{abstract}
Amanda Motta Castro ${ }^{1}$
Resumo: Os escritos aqui apresentados têm como objetivo principal fazer uma reflexão sobre relações de gênero e sobre a formação docente realizada no estado do Amazonas, na Universidade do Estado do Amazonas (UEA), dentro do Plano Nacional de Formação de Professores (PARFOR). O PARFOR é um programa do Governo Federal oferecido na modalidade presencial, este é um Programa emergencial instituído para atender ao disposto no artigo 11, inciso III do Decreto n ${ }^{\circ}$ 6.755, de 29 de Janeiro de 2009, implantado em regime de colaboração entre a Capes, os estados, municípios e as Instituições de Educação Superior (IES). O objetivo deste programa é realizar a formação superior de docentes que já atuam na Educação Básica e não possuem curso de ensino superior. Aqui, será debatida a experiência de orientação de 21 estudantes docentes do PARFOR entre os meses de Junho a Outubro de 2015, no município de Tefé, localizado no Médio Solimões, no Estado do Amazonas. Articulando gênero e Educação popular, este texto faz uma discussão sobre a questão de gênero neste contexto.

Palavras-chave: Educação Popular. Gênero. Formação docente. PARFOR. Amazonas.
\end{abstract}

\section{AMAZON: WOMEN AND TEACHER TRAINING IN PARFOR}

\begin{abstract}
The main objective of this text is to reflect on gender relations and the teacher training realized in the Amazonas state, at the State University of Amazonas (UEA), by the National Teacher Training Plan (PARFOR). PARFOR is a Federal Government program offered at classroom modality. It's an emergency program established to comply with the provisions of the article 11, item III of the Decree $\mathrm{N}^{\circ}$. 6,755, of January 29, 2009 and it was implemented in collaboration with Capes, the states, municipalities and Higher education institutions (IES). This program objective is to accomplish the higher education training of teachers who already work in Basic Education and do not have a higher education course. At this text it will be discussed the 21 PARFOR teaching students orientation experience realized between the months June and October 2015, in Tefé, city located in Middle Solimões, in Amazonas State. Articulating gender and popular education, this text makes a discussion about the gender issue at this context.
\end{abstract}

Keywords: Popular Education. Gender. Teacher training. PARFOR. Amazonas.

\footnotetext{
${ }^{1}$ Professora do Programa de Pós Graduação em Educação da Universidade Federal do Rio Grande do Sul/FURG e docente do Departamento de Educação da mesma instituição. Doutora pelo programa de Pós-Graduação em Educação da Universidade do Vale do Rio dos Sinos/UNISINOS; foi bolsista CAPES durante (2009-2015). É mestra em Educação (2011); Licenciada em Pedagogia (2000) e graduanda em Filosofia (2018). Realizou Estágio de doutoramento na Universidad Autonoma Metropolitana del México - UAM, no departamento de Antropologia. Com o olhar na América Latina, tem-se ocupado com os seguintes temas de pesquisa: feminismo, educação popular e processos de exclusão social. Contato: motta.amanda@gmail.com
} 


\section{REFLEXÕES INICIAIS}

"Globalizemos a Luta! Globalizemos a Esperança!"”

Via Campesina

FIGURA 1 - Encontro das Aguas. Manaus/AM

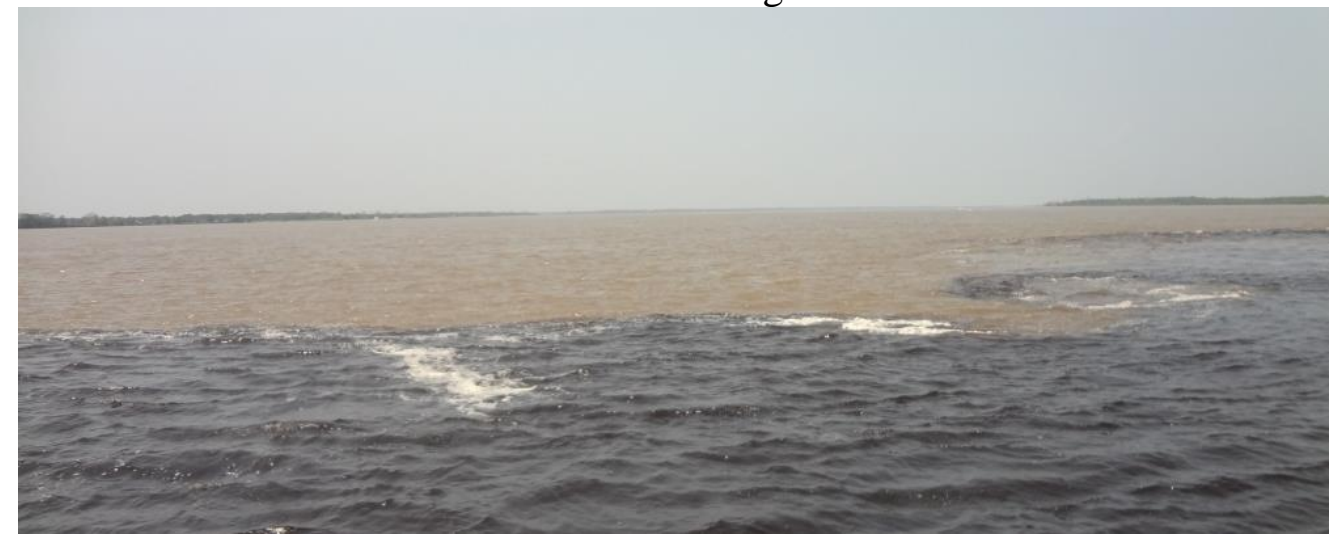

Fonte: Amanda Motta Castro, 2015

Os escritos aqui apresentados têm como objetivo fazer uma discussão sobre relações de gênero na formação docente realizada na Universidade do Estado do Amazonas - UEA em um lugar do mundo especial: a Amazônia.

Particularmente, penso que todas as pessoas deveriam conhecer a Amazônia, nem que seja uma única vez. Há algo de mágico na floresta, nos rios e na imensidade de vida que encontramos na Amazônia.

Entretanto, entre as inúmeras belezas da Amazônia, existe uma luta sendo travada. Luta por terra, escola, saúde, trabalho e pelo direito de ter uma vida melhor. Esta região ainda carece de reforma agrária, saúde e Educação.

De acordo com Antônio Canudo (2012), após o golpe militar no Brasil, os militares criaram um programa com a meta de levar desenvolvimento para a região norte do Brasil. Como o slogan "levar homens sem terra para uma terra sem homens", o governo brasileiro levou, de várias regiões do Brasil, pessoas para trabalharem e viverem na região norte.

Segundo a Comissão Pastoral da Terra (CPT), esse movimento desastroso levou a classe trabalhadora desta região a sofrer ainda mais com baixos salários, exploração e precariedade, ressaltando que os desdobramentos deste ato ainda são presentes na 
região Norte. Esse foi um dos pontos que levaram a classe trabalhadora dessa região e os movimentos sociais a se organizarem e conquistarem avanços como, por exemplo, a criação, em 1971, da CPT. Na luta pela terra, morreu Chico Mendes ${ }^{2}$, Irmã Dorothy ${ }^{3}$ e, em 1996, ocorre, no Pará, o massacre ${ }^{4}$ de integrantes do Movimento do Sem Terra (MST).

Camponeses, ribeirinhos, extrativistas, indígenas: quem vive na maior floreta do mundo? A Amazônia tem uma gama de populações que vivem na floresta. Desse modo, algumas vezes fica a dúvida: como nomear as populações da floresta? Sobre essas questões, o militante do Conselho Nacional das Populações Extrativistas - (CNS) Huefeson Falcão explica que:

No norte, temos várias pessoas vivendo na floresta que são de diferentes segmentos. Temos a população indígena, extrativista, quilombolas, ribeirinhas, quebradoras de coco babaçu entre outras que é difícil numerar porque são muitas. A população extrativista são as pessoas que vivem principalmente em áreas de preservação, vivem a partir da agricultura familiar, pesca e artesanato. E a população ribeirinha (conceito hoje pouco utilizada) vive na beira dos Rios da Amazônica sobrevivendo principalmente da pesca. A CNS esta em parceria com o MST e a CPT, embora hoje quem está na luta pela garantia dos direitos

\footnotetext{
${ }^{2}$ Francisco Alves Mendes Filho, mais conhecido como "Chico Mendes" (Xapuri, 15 de dezembro de 1944 — Xapuri, 22 de dezembro de 1988), foi um seringueiro e sindicalista brasileiro. Sua luta pela preservação da Amazônia o tornou conhecido internacionalmente e foi a causa de seu assassinato. Chico Mendes foi assassinado no dia 22 de dezembro de 1988, em Xapuri, no Acre, vítima de um tiro de espingarda calibre 20. O crime foi atribuído a Darly Alves da Silva e seu filho Darci Alves Pereira. Um das demonstrações de sua luta foi em março de 1987, quando Chico fez um discurso cheio de denúncias na reunião do Banco Interamericano de Desenvolvimento (BID) em Miami (EUA). Pediu a suspensão do financiamento do organismo para o prosseguimento da construção da BR-364, que cortava o estado de Rondônia e se estenderia até o Acre. A construção da estrada tinha provocado danos significativos para os seringueiros de Rondônia, em razão do desmatamento e das queimadas provocadas pelos fazendeiros. Com o apelo, o BID suspendeu o financiamento para a expansão da BR-364 e passou a exigir do governo brasileiro estudos de impacto ambiental na Amazônia. Além do BID, o Senado dos Estados Unidos, onde o seringueiro também foi convidado a falar, fez recomendações a diversos bancos que patrocinavam projetos desenvolvimentistas na região. Alertou-os de abusos ao meio ambiente, como os ocorridos em Rondônia. Outro episódio fez crescer a ira dos fazendeiros acreanos contra Mendes: o reconhecimento ao seu trabalho pela Organização das Nações Unidas. Em 1987, a ONU conferiu a ele o Prêmio Global 500, de preservação ambiental. Chico Mendes foi o único brasileiro, até hoje, a conquistar este título. Fonte: http://institutochicomendes.org.br/site/. E http://www.icmbio.gov.br/portal/. Acesso em: out. 2015.

${ }_{3}^{3}$ Dorothy Stang nasceu nos Estados Unidos em 1931. Veio para o Brasil em 1966 e era naturalizada brasileira. Morava em Anapu, no Pará, a $500 \mathrm{Km}$ de Belém. Anapu é uma pequena cidade cortada ao meio pela rodovia Transamazônica. O seu trabalho pastoral era a catequese e a formação de Comunidades cristãs. Além disso, Irmã Dorothy atuava em várias cidades e vilarejos rurais da região do Xingu. Ela buscava, também, a geração de emprego e renda, com projetos de reflorestamento em áreas degradadas. Seu trabalho focava-se, também, na minimização dos conflitos fundiários existentes na região. Atuou em várias pastorais sociais do Pará, principalmente na Comissão Pastoral da Terra. Devido ao seu trabalho junto aos agricultores, ganhou vários prêmios em nível nacional e internacional. Participava, ativamente, na luta dos trabalhadores e trabalhadoras do campo contra a grilagem e a devastação da floresta. Ajudou a fundar a primeira escola de formação de professores na rodovia Transamazônica. Irmã Dorothy recebeu diversas ameaças de morte. Pouco antes de ser assassinada, declarou: "Não vou fugir nem abandonar a luta desses agricultores que estão desprotegidos no meio da floresta. Eles têm o sagrado direito a uma vida melhor, numa terra onde possam viver e produzir com dignidade, sem devastar". Dorothy Stang foi assassinada com seis tiros aos 73 anos, no dia 12/02/2005, em uma estrada de terra de difícil acesso, a $53 \mathrm{~km}$ da sede do município de Anapu. O fazendeiro Vitalmiro Moura, acusado de ser o mandante do crime, foi condenado a 30 anos de prisão. Fonte: http://www.mst.org.br/2015/02/11/dez-anos-apos-o-assassinato-da-irma-dorothy-o-sangue-aindacorre-na-floresta.html. Acesso em: set. 2015.

${ }^{4}$ O Massacre Eldorado dos Carajás aconteceu durante uma marcha de integrantes do MST para Belém, em 1996. Na ocasião, os sem-terra bloqueavam a rodovia PA-150 para forçar a desapropriação da área da fazenda Macaxeira, de 35 mil hectares ocupada por 1500 famílias havia 11 dias. O coronel Mário Collares Pantoja mandou policiais para o local a fim de conter a ação do MST. A operação da polícia, que envolveu 155 PMs armados, levou à morte 19 trabalhadores; deixou outros 69 mutilados e uma centena de feridos. Por isso, o dia 17 de abril de 1996 acabou entrando para a história como uma das ações policiais mais violentas do Brasil. Fonte: http://www.cartacapital.com.br/sociedade/mst-bloqueia-rodovias-para-lembrar-massacre-de-eldorado-dos-carajas-9946.html. Acessado em: set. 2015.
} 
dos povos da Amazônia é o CNS. (Entrevista com Huefeson Falcão em outubro de 2015)

Portanto, a partir da fala acima, podemos concluir que a turma do PARFOR aqui relatada é constituída, sobretudo, de pessoas oriundas de famílias ribeirinhas e extrativistas que vivem na Floresta Amazônica. Quem faz a práxis da educação neste contexto? A Educação do campo. A autora Roseli Caldart $(2012$, 2015) explica que a Educação do campo é um conceito em construção e que este conceito abarca todas as pessoas que vivem da terra e em zonas rurais. A educação do campo engloba a luta pela educação, terra, território, reforma agrária e soberania alimentar. Dessa forma, percebemos que as populações da floresta estão no bojo das discussões da Educação do Campo.

\section{PARFOR E FORMAÇÃO DOCENTE}

FIGURA 2 - Escola Municipal Peixinho Dourado. Zona rural de Maraã/AM

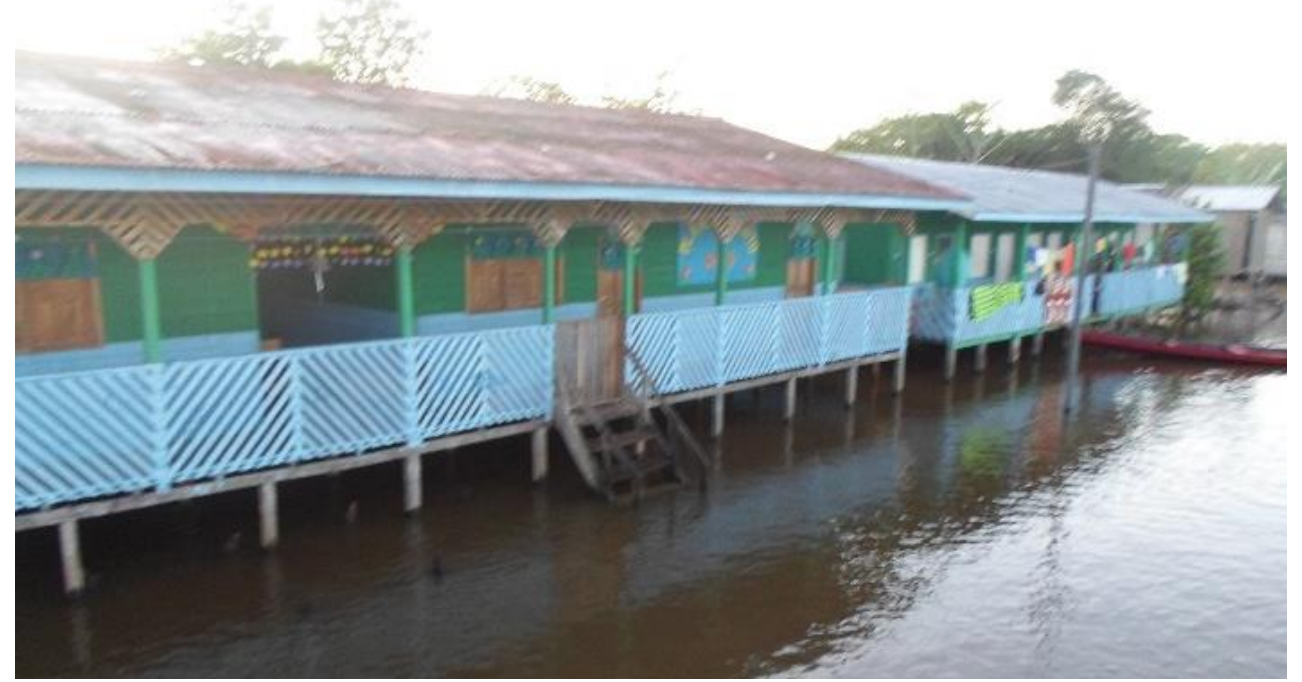

Fonte: Aluna A, 2015.

FIGURA 3 - Escola Henrique Lima. Zona rural da comunidade São José do Igarapé $\mathrm{Açu/AM}$ 


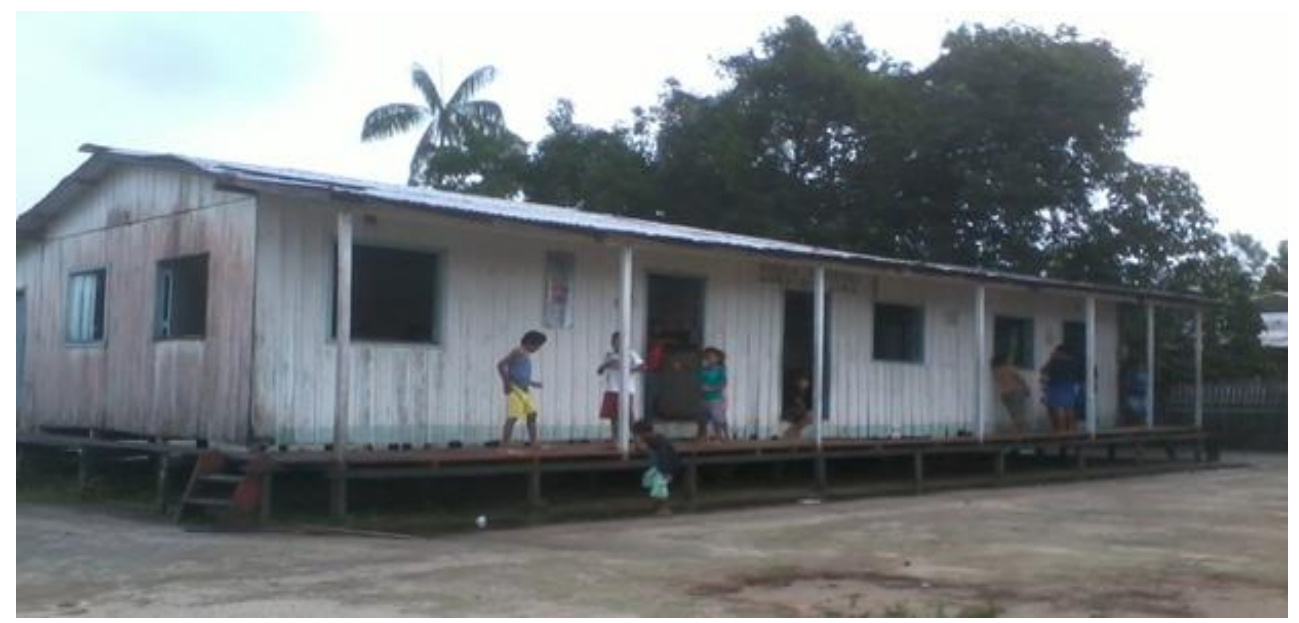

Fonte: Aluno H, 2014.

De acordo com a Coordenação de Aperfeiçoamento de Pessoal de Nível Superior - (CAPES), o PARFOR, na modalidade presencial, é um Programa emergencial instituído para atender ao disposto no artigo 11, inciso III, do Decreto $\mathrm{n}^{\circ}$ 6.755, de 29 de janeiro de 2009, implantado em regime de colaboração entre a CAPES, os estados, municípios o Distrito Federal e as Instituições de Educação Superior (IES). O objetivo principal deste programa é fomentar a oferta de educação superior, gratuita e de qualidade, para docentes em exercício na rede pública de educação básica, para que estes profissionais possam obter a formação exigida pela Lei de Diretrizes e Bases da Educação Nacional - LDB e, assim, contribuir para a melhoria da qualidade da educação básica no País.

Para concorrer à vaga nos cursos ofertados, os docentes devem: a) realizar seu cadastro e pré-inscrição na Plataforma Freire ${ }^{5}$; b) estar cadastrado no Educacenso na função Docente ou Tradutor Intérprete de Libras na rede pública de educação básica; e c) ter sua pré-inscrição validada pela Secretaria de Educação ou órgão equivalente ao qual estiver vinculado.

Os dados da CAPES apontam que, desde sua criação até o ano de 2014, foram implantadas 2.428 turmas, em 451 municípios, localizados em 24 unidades da federação. Atualmente, existem 51.008 docentes da educação básica, frequentando os

\footnotetext{
5 A Plataforma Freire, criada pelo Ministério da Educação, é a porta de entrada para docentes da educação básica pública, no exercício do magistério, para as instituições públicas de ensino superior. Sua função é colocar em prática o Plano Nacional de Formação docente da Educação Básica, além de informar a previsão de oferta de curso, as instituições, as modalidades de formação, entre outras. Fonte: http://portal.mec.gov.br/component/content/article?id=13829:veja-passo-a-passo-como-usar-aplataforma-freire. Acesso em: set. 2015.
} 
cursos do PARFOR e 12.103 docentes já concluíram sua formação. No gráfico abaixo, temos os números e regiões do PARFOR em 2014.

FIGURA 4 - números e regiões do PARFOR em 2014

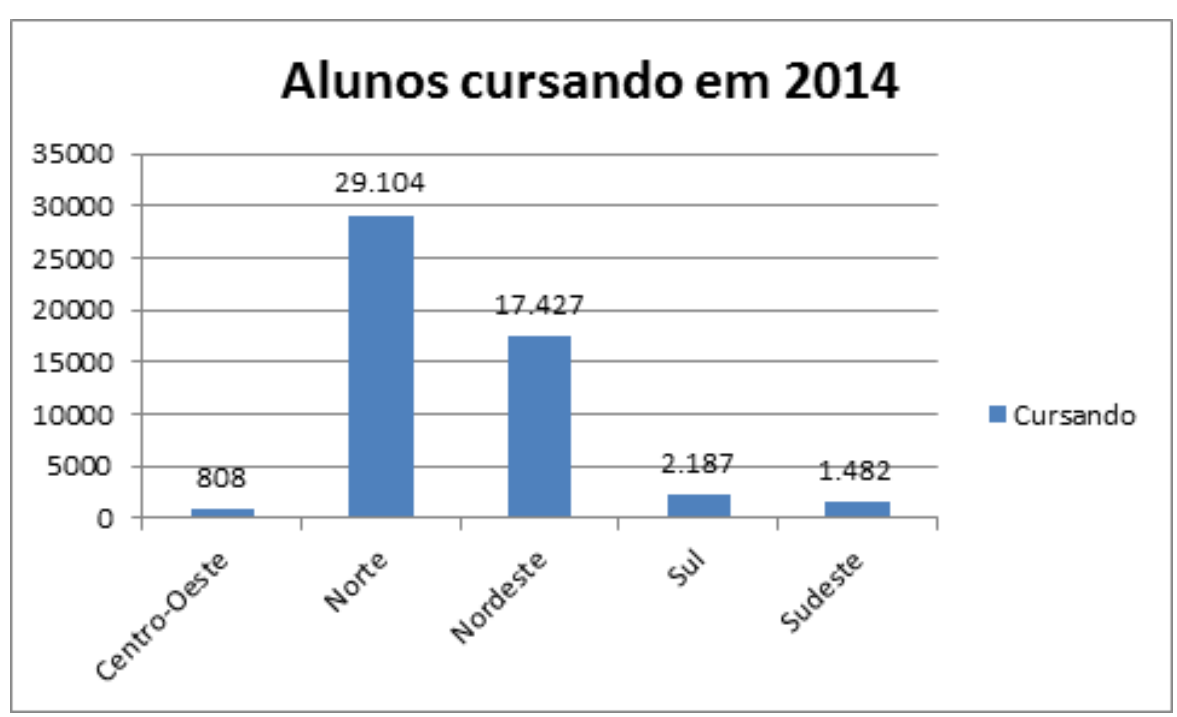

Fonte: http://www.capes.gov.br/educacao-basica/parfor

Os dados mostram a importância do PARFOR na formação docente de Norte a

Sul do Brasil. Iniciei minha contribuição neste projeto com uma turma do PARFOR na UEA, localizada no município de Tefé, ${ }^{6}$ em junho de 2015 . O objetivo principal foi orientar 21 Trabalhos de Conclusão de Curso. A turma era composta com 13 mulheres e 8 homens.

A experiência de vida que constitui esses docentes é marcada por uma vida difícil, com muitas limitações. A maioria pisou na escola pela primeira vez depois dos 10 anos, como podemos observar no relato da aluna A:

Comecei a estudar quando tinha oito anos, na Escola Municipal Santa Teresa no ano de 1984 minha $1^{\text {a }}$ (primeira) alfabetizadora se chamava dona Zezé, era muito tradicional, lembro-me de um ato que me traumatizou muito "Ela mandou todos" lerem em silêncio e eu não sabia lê e comecei a olhar para o quadro e balbuciar e ela ouviram e meteu o lápis em minha boca com tanta força que feriu minha gengiva e foi a partir dali que comecei a me interessar pelas letras e logo aprendi a lê.

\footnotetext{
${ }^{6}$ Tefé é um município brasileiro do interior do estado do Amazonas, Região Norte do País. Pertencente à Mesorregião do Centro Amazonense e Microrregião de mesmo nome, sua população, de acordo com estimativas do Instituto Brasileiro de Geografia e Estatística (IBGE), em 2015, era de 62444 habitantes. Tefé está distante $523 \mathrm{~km}$ de Manaus, capital do estado. Fonte: http://www.aam.org.br/prefeituras/372prefeitura-municipal-de-tefe. Acessado em: out. 2015.
} 
Do $1^{\mathrm{a}}$ a $3^{\mathrm{a}}$ série (ano) estudei na mesma escola e cada ano uma professora diferente e sempre busquei ser uma boa aluna. Meu primário foi de muita luta, pois meus pais não tinham condições de morar na cidade e se mudaram para um sitio, pois eles precisavam trabalhar eles não tinham empregos para nos manter. $O$ sitio ficava na estrada da Agrovila, nesta época eu tinha 10 (dez) anos e cursava terceira série e meus pais preocupado com nosso aprendizado, matricularam todos no mesmo horário, ele nos levava cedo para a roça e quando davam 10 horas íamos para casa se arrumar, pois $1^{a}$ hora tinha que estar no colégio que ficava uns oito quilômetros da escola, chegávamos tão cansados, mas cheio de vontade de aprender e graças a Deus foi só um ano que eles moraram lá, logo meu pai consegui um trabalho e se mudamos de novo para a cidade. (Aluna A no PARFOR, 2015)

A fala da aluna A foi cheia de emoção e não apenas sua fala, a emoção e o esforço foi uma marca em cada encontro de orientação. De fato, o empenho e a coragem sempre foram uma característica muito admirada por mim na minha turma do PARFOR. Algumas pessoas vinham de barco por horas, deixavam suas famílias e suas crianças. E todas as pessoas eram as primeiras a concluírem um curso superior em suas famílias. Com tanta luta e dificuldades, para mim, todas já são vencedoras e vencedores, por todos os obstáculos e pela ausência de direitos que viveram. O relato da aluna B mostra um pouco das dificuldades encontradas por este coletivo para a chegada até a conclusão de um curso superior:

Minha historia na escola começou na Escola Estadual Alcijara Gadelha de Queiroz, eu o mais velho tinha 15 (quinze anos) na época, me sentia muito envergonhado de ir para a escola, devido a minha idade ser um pouco avançada para a série que eu fazia, mesmo assim não desisti e fui em frente na busca de meu objetivo que era passar de ano, e com muita perseverança, otimismo e dedicação conseguir chegar ao final do ano atingindo um resultado positivo, graças ao professor Joel que era um bom educador e me incentivou bastante para estudar. (Aluna do PARFOR, 2015)

Marcou, também, a importância e a persistência dos pais, sobretudo das mães dos estudantes do PARFOR. A grande maioria não sabia ler nem escrever, outras liam pouco e sabiam escrever seus nomes, contudo essas mulheres travaram batalhas impressionantes para poder oportunizar o estudo formal seus filhos e filhas: Mudaram para a cidade (porque na zona rural não tinha escolas), brigaram com maridos, batiam na porta da prefeitura exigindo escola para suas crianças; nas palavras da aluna $\mathrm{C}$, ela narra o deslocamento para a cidade: 
Desde criança, e durante a minha infância morei na zona rural onde hoje é a Reserva Mamirauá localizado as margem direita do rio Japurá com uma distância de três horas de viagem de motor rabeta até a comunidade, desde cedo vivenciei a dura realidade da vida. Aos 07 anos de idade tinha que trabalhar pela manhã e tarde na roça porque naquele tempo não havia escola na comunidade era muito difícil encontrar um professor poucas pessoas tinham o conhecimento da leitura e da escrita. O meu pai era alfabetizado minha mãe não, mas eles tinham um grande sonho que era colocar eu numa escola para que pudesse ter meus estudos, pois acreditavam muito na educação, mas isso se tornou uma realidade somente quando completei 10 anos de idade recordo que meus pais arrumaram todas as coisas que tínhamos colocou dentro de um barco e seguiu-se a viagem à cidade de Tefé, isso tudo para podermos estudar. (Aluna do PARFOR, 2015)

\section{O relato da Aluna D:}

Não foi fácil minha adaptação no meio urbano, porque meus pais não tinham emprego e nenhum ganho salarial. Então meu pai teve que continuar sua profissão de pescador, tendo que ficar longe da família por vários dias. E minha mãe continuou costurando, profissão que exercia desde muito cedo, pois a mesma perdera a sua mãe ainda criança. E diante seus relatos, me incentivava a lutar por um futuro melhor, aproveitando as oportunidades de estudo. Foi algo maravilhoso quando minha mãe disse agora você vai estudar filha, fiquei tão feliz que não conseguia dormir naquela noite, parece que a noite se estendeu um pouco, porque demorou amanhecer, mas a felicidade maior foi quando comecei a conhecer as letras, e lia as palavras por onde passava, muitas vezes eu lia do jeito que estavam escritas, e minha mãe me corrigia com o pouco de conhecimento que tinha. (Aluna D, 2015)

Desse modo, a luta da minha turma de formandos e formandas do PARFOR é uma luta que vem de muito tempo, o que, durante as orientações e a finalização do trabalho, foi várias vezes dito.

Logo, para a realização e finalização das orientações, retomei, muitas vezes, as palavras de Conceição Paludo (2012), quando ela afirma que, para fazer um trabalho no campo da Educação popular na Educação formal, (e aqui na Universidade) é preciso estar com um pé na sociedade, compreendendo o contexto de vida que constituíram as pessoas que estão neste espaço e um pé na escola para, então, compreendermos as dificuldades de leitura, escrita, interpretação e uso de tecnologias, resultado de uma educação básica deficitária. Esse déficit ocorre porque houve a total ausência do estado no que tange aos direitos básicos dos cidadãos e das cidadãs, para as quais o direito a educação formal foi negado. 
Para Maria Araujo (2012), no Brasil, 18 milhões de pessoas são excluídas do mundo das letras e do conhecimento formal. A mesma autora denuncia que a taxa de analfabetismo é três vezes maior na zona rural do que na urbana. Mas há esperança de que os docentes formados no PARFOR que vão atuar, principalmente nas áreas rurais do Médio Solimões, no estado do Amazonas, ajude na construção e no fortalecimento de uma educação do campo. Caldart (2012) pontua que a educação do campo esta pautada nas seguintes questões: "no campo: o povo tem direito a uma educação onde vive. Do campo: o povo tem direito a uma educação desde o lugar que esta e com sua participação a partir da sua cultura e das necessidades humanas e sociais” (p 264).

\section{FORMAÇÃO DOCENTE: gênero, educação popular e patriarcado}

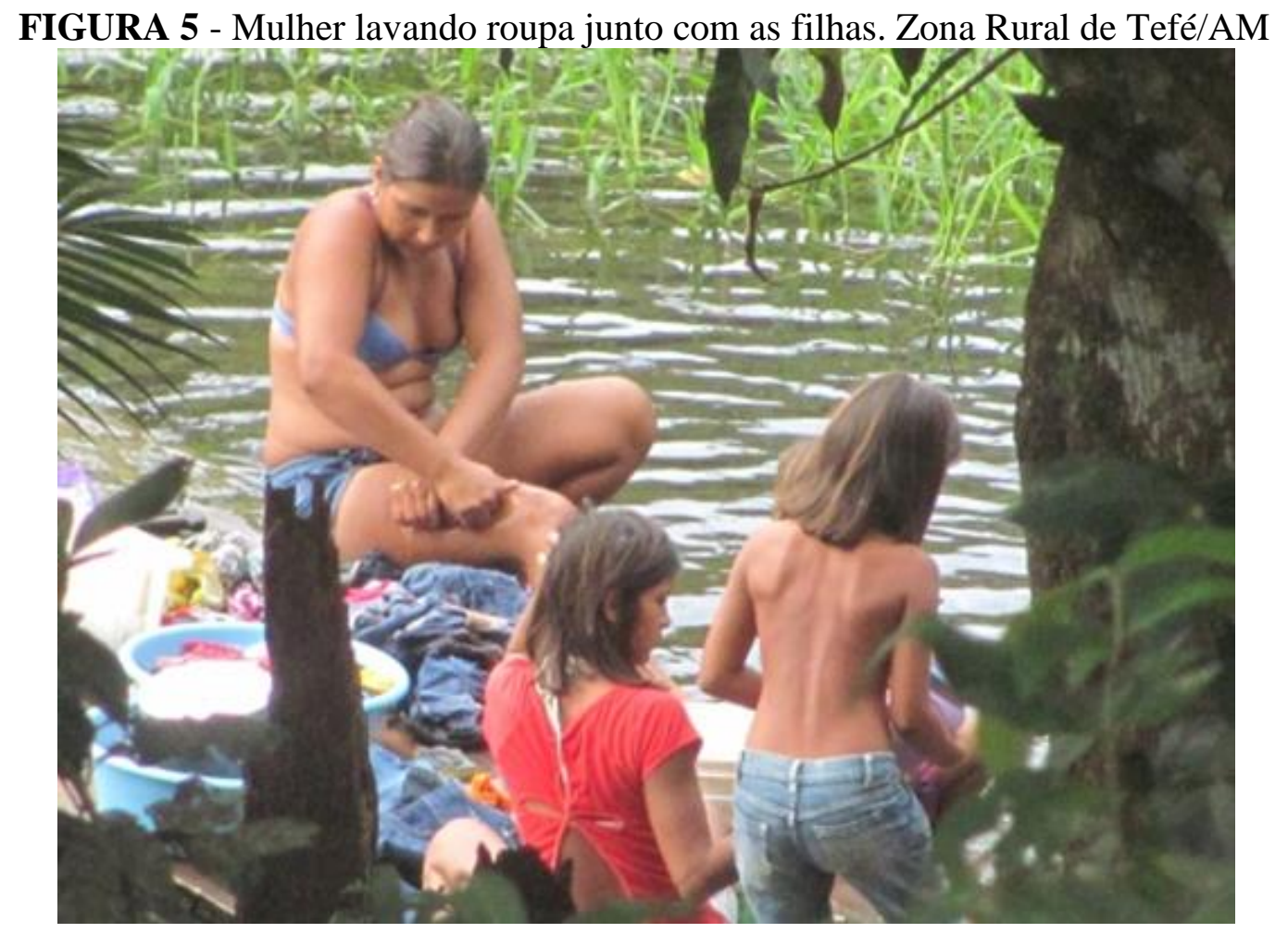

Fonte: Nickele Góes, 2015

Durante este trabalho, meu olhar esteve voltado para dois espaços que me constituem: primeiro, a Educação Popular e, segundo, os Estudos Feministas. A Educação Popular é um conceito que também é de ordem política, ideológica e de lutas. Ela abrange os processos desenvolvidos no cotidiano da experiência a partir dos processos formais e não formais de ensino e aprendizagem (PALUDO, 2008; 
BRANDÃO, 2007). Assim, a Educação Popular pode ser pensada como possibilidade educativa incentivada por governos ${ }^{7}$ ou organizações civis. Nessa perspectiva, a educação é realizada com o/a outro/a e não sobre o/a outro/a. Para José Francisco de Melo Neto (2005), esta educação está a serviço da promoção do outro, promoção das pessoas, de seus conhecimentos e experiências ${ }^{8}$. De acordo com o mesmo autor, a "Educação Popular manifesta-se por meio do insistente desejo de criação do conhecimento que busque fazer história" (NETO, 2008, p. 5).

Compõe, aqui, meu olhar, além da Educação Popular, o conceito de Gênero. Este conceito é compreendido, também, como sendo de ordem política e ideológica, construído no bojo das lutas do movimento social de mulheres. Para Graciela Hierro (2007), nas lutas feministas existem duas vertentes: uma prática, que é realizada no movimento social; e outra teórica. A mesma autora afirma que "la teórica consiste en el estudio de la condición feminina y la creación de la cultura feminina". A autora afirma ainda que "los estudios de mujeres son el brazo académico del movimento feminista". (idem, p. 127). Desse modo entendo o conceito de gênero como desenvolvido no bojo dos estudos feministas, ideologicamente e politicamente produzido nas lutas dos movimentos sociais de mulheres.

De acordo com Marta Lamas (2002), o conceito de gênero começa a ser utilizado nas ciências sociais como categoria a partir da década de 1970. Desde então, a Academia passa a trabalhar com o conceito de gênero, abordando como são construídos culturalmente o ser homem e o ser mulher. Lamas (2002) destaca, ainda, que "hay que tener siempre presente que entre mujeres y hombres hay más semejanzas como especie que diferencias sexuales" (LAMAS, 2002, p. 37).

Nesta abordagem, gênero é a aprendizagem que acontece nas relações socialmente produzidas entre homens e mulheres e destes entre si. Portanto, homens e mulheres aprendem a ser o que são na cultura em que estão inseridos.

\footnotetext{
${ }^{7}$ No que diz respeito ao governo, a Educação Popular tem sido pensada por diversos governos de esquerda, sobretudo da América Latina. No Brasil, podemos citar as escolas itinerantes do MST e os movimentos de Alfabetização de Adultos, ambos embasados, teoricamente, nos pressupostos da Educação Popular. No estado do Rio Grande do Sul, as escolas itinerantes surgiram em 1997; atendiam mais de 700 crianças que viviam em acampamentos do MST. Em 2009, a então governadora do Estado do Rio Grande do Sul, Yeda Crusius, determinou o fechamento das escolas itinerantes do MST. Sua principal argumentação era de que, além dos gastos, as escolas tinham "ideologia". Todavia, fica a pergunta: As demais escolas são isentas de ideologia?

8 Definição compartilhada pelo pesquisador José Francisco de Melo Neto, durante a realização do minicurso da 35. ${ }^{a}$ Reunião da ANPED do GT 06, em Porto de Galinhas, 2012.
} 
Seguindo este referencial, as pessoas adultas nos ensinam, desde a infância, como devemos ser homens ou mulheres para sermos socialmente aceitos (SAFFIOTI, 2004). Ou seja, a velha e boa conceituação de Simone de Beauvoir (2009) configura-se como eixo: aprendemos a ser mulheres e homens. E, como estamos inseridos no contexto histórico-patriarcal, aprendemos a ser heterossexuais (homens e mulheres). As mulheres aprendem a ser de alguém e para os outros (LAGARDE, 2011); e o homem aprende que deve dominar a mulher, mesmo que ela possa ser a "rainha do lar" - leiase: a madresposa, que produz a manutenção da lógica patriarcal. (LAGARDE, 2011; PISANO 2001, 2004).

$\mathrm{O}$ conceito de gênero se interpenetra com o conceito de patriarcado, pois é o conceito de patriarcado que explica a estrutura social que inferioriza as mulheres. Para Marcela Lagarde (2012), a definição de patriarcado foi realizada em 1861 por Henry Maine, que o define como a lei do Pai.

Didaticamente, Ivone Gebara (2007, p. 19) explica: "sociedade patriarcal significa que a maneira pela qual somos educados é marcada por concepções que valorizam um referencial teórico masculino mais do que o feminino". Para Hierrro (1990, p. 05), “el patriarcado que justifica su rechazo tildándola de la culpable de los males que aquejan la humanidad. El exterminio de las brujas en la Edad Media, no se debió al hecho de que poseían poderes ocultos, sino por ser mujeres".

Lagarde (2011, p. 91) define este conceito: "El patriarcado es uno de los espacios históricos del poder masculino que encuentra su asiento en las más diversas formaciones sociales y se conforma por varios ejes de relaciones sociales y contenidos culturales". Segundo Neuma Aguiar (2000, p. 01), “o patriarcado se pauta pela dominação do público sobre o privado".

Sendo assim, historicamente, o que é produzido pelas mulheres, no cotidiano privado, é avaliado como de menor valor social, se comparado ao que é produzido pelos homens nos espaços públicos.

Contudo, o patriarcado, ao negar às mulheres o espaço público, não necessariamente dá poder às mesmas no espaço privado:

Às mulheres não é negado somente o acesso ao espaço público, mas também está limitado o exercício de decisão no âmbito privado. Este espaço em última instância está sob a autoridade do patriarca, pai e senhor. Uma consequência desta assimetria de poder está na definição e prescrição dos valores e normas que irão regrar a sociedade. Estes vão 
seguir os parâmetros masculinos e serão percebidos como "universais" enquanto que os valores femininos serão "especiais" ou particularmente "particulares/peculiares. (NEUENFELDT, 2006, p. 85).

Dessa forma, neste lugar onde as mulheres desenvolveram um cativeiro aconchegante (LAGARDE, 2011), o patriarcado também lhes nega o poder de decisão. Nesse espaço, a decisão final, em grande medida, também continua sendo dos homens.

A autora Martha Nussbaum (2000) diz que as mulheres são pessoas de segunda categoria no mundo. Sua afirmação se sustenta porque as mulheres são mais mal alimentadas; têm menor nível de saúde; são mais vulneráveis ao abuso sexual, à violência física; são menos alfabetizadas do que os homens; ganham menos que os homens e sofrem mais assédio em espaços de trabalho do que os homens (NUSSBAUM, 2000). A pesquisadora Sandra Duarte de Souza pontua que:

Um bilhão de mulheres, ou uma em cada três do planeta já foram espancadas, forçadas a ter relações sexuais ou submetidas a algum tipo de abuso. $50 \%$ das latino-americanas experimentaram algum tipo de violência. No Brasil estima-se que a cada 15 segundos uma mulher é agredida, normalmente em seu lar, por uma pessoa com quem mantem relações afetivas. (SOUZA, 2009 p. 42, 43)

Tendo como ponto de partida os dados apontados pelas duas autoras e a experiência, a formação docente entre homens e mulheres não é igual, pois as mulheres não são colocadas socialmente em pé de igualdade como os homens. Durante a formação no PARFOR, as mulheres falavam sobre a dupla jornada de trabalho, cuidado com os filhos e filhas, pressões do marido ou companheiro sobre estar mais tempo em casa, violência doméstica, falta de dinheiro, solidão e abandono.

Com um aperto no coração, ouvia a Aluna D dizer que: "Minha mãe teve nove filhos, onde sete faleceram quando pequenos, e só nos duas sobrevivemos." (aluna D, 2015). Esse depoimento agrega a outros, como o da aluna F:

O meu és marido vivia agredindo verbalmente que em uma de nossas discussões me ofendeu dizendo que a amante eram represente do programa MOVA BRASIL, tinha graduação completa e ganhava muito dinheiro e não precisava do dinheiro dele, com essas palavras despertou o leão que existem dentro de nós, em virtude do mesmo esse é meu maior sonho de concluir uma faculdade antes dos meus cinquenta anos. (Aluna F, 2015)

A partir da vivência dessas mulheres, verificamos o quanto ainda precisamos 
avançar no campo dos Estudos Feministas e da Militância, para conquistarmos direitos igualitários, justos e construirmos uma sociedade diferente. Assim, retomamos os escritos Feministas que vão apontar que a função social das mulheres é o lar, o cuidado e o corpo para outros (Lagarde, 2011).

Dentre as 13 (treze) mulheres que integravam a turma, as questões domésticas estavam fortemente relacionadas. Inclusive, o TCC foi escrito entre as panelas e o cuidado com as crianças. A simultaneidade entre o acadêmico e o doméstico estava posto. Porém, para meus 8 (oito) alunos homens, as questões domésticas e de cuidado não eram relatadas. A maioria deles, inclusive, falavam com orgulho que contavam com a "rainha do lar" ou com a "patroa"; quando chegavam a casa, descansavam. Para as mulheres não, chegar a casa era sinônimo de trabalho dobrado.

Conduto, apesar das imensas dificuldades que as mulheres encontraram, a formação no PARFOR possibilitou a estas mulheres um curso superior, o que ajuda a romper a lógica patriarcal de mulheres no privado e homens no publico. Durante as orientações, essa questão foi algumas vezes mencionada: "agora eu só vou professora, agora sim, tenho um curso superior, vou poder ser mais independente” (aluna A. 2015). Dessa forma, a formação é um dos caminhos possíveis para a busca pela igualdade entre os sexos.

\section{REFLEXÕES FINAIS: a experiência dos povos da floresta}

FIGURA 6 - Menina pescando. Zona Rural de Tefé/AM 


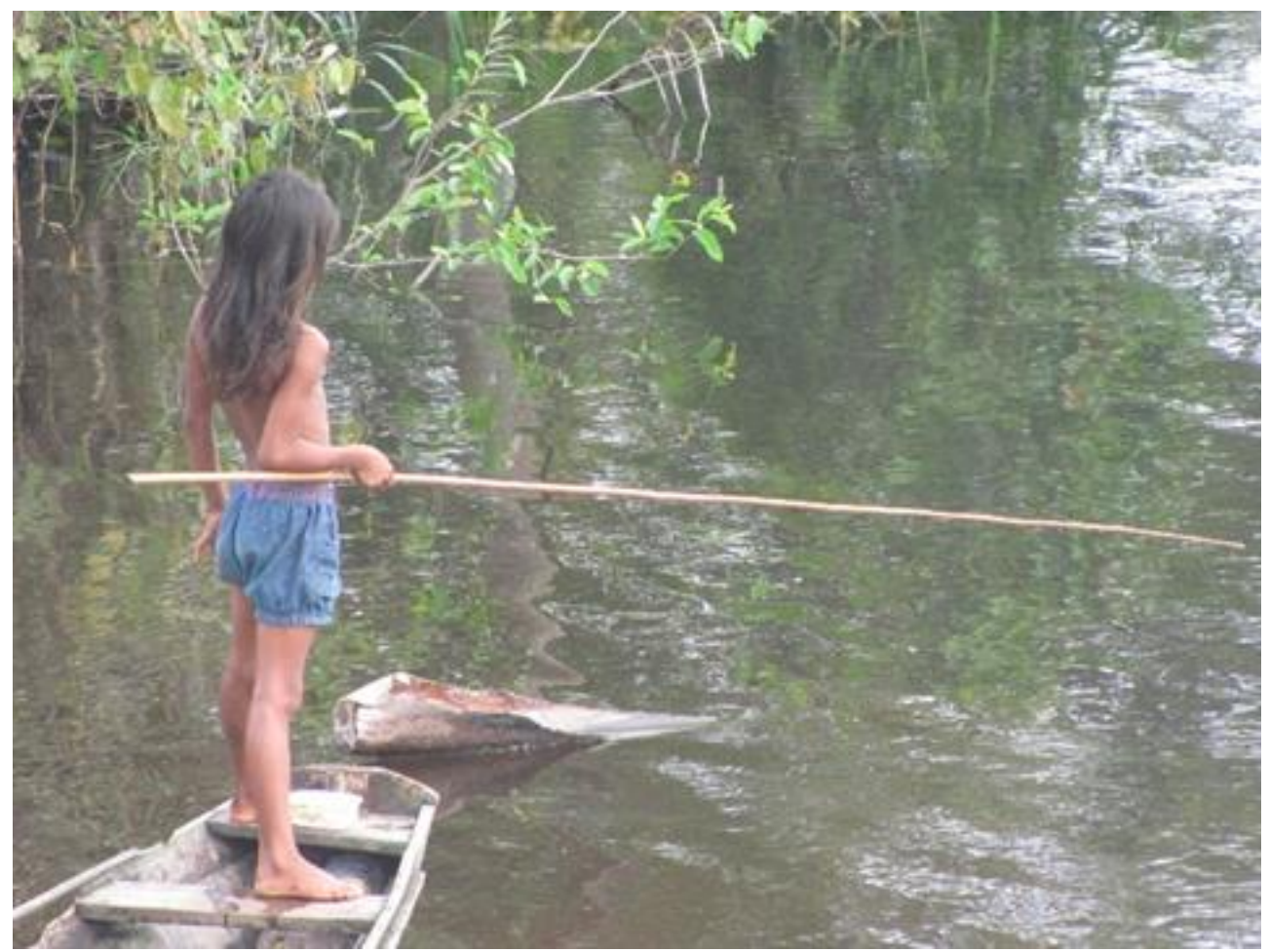

Fonte: Nickele Góes, 2015

Tanto os Estudos feministas quanto à Educação Popular apontam para a importância da experiência, ambas a consideraram como desencadeadora da produção do conhecimento.

As mulheres têm uma experiência histórica e cultural diferenciada da masculina; contudo, nas margens onde as mulheres teceram suas experiências, encontramos experiências cruciais para a pesquisa com mulheres, o que nos leva a valorizar o conceito de experiência.

Percebemos que trazer o conhecimento ateórico, tecido em espaços do cotidiano, de onde surge a experiência das mulheres, tem sido uma luta feminista desde seu início, sobretudo no que tange a reconhecer as experiências das mulheres como conhecimento. Nesse sentido, a epistemologia feminista rompe paradigmas estabelecidos ao descobrir e reconhecer a vida e a produção das mulheres ao longo da história e de tantas outras que hoje fazem histórias e produzem, como as mulheres de nossa pesquisa. Em alguma medida, tentamos fazer com que suas produções saiam da invisibilidade, que se percebam como atuantes em sua própria história, porque esta não está dada. Como afirma Freire (1999, p. 58), 
pelo mundo não é predeterminada, preestabelecida. Que meu "destino" não é um dado, mas algo que precisa ser feito e de cuja responsabilidade não posso me eximir.

As palavras de Freire nos fazem refletir o quanto a experiência pode ser mobilizadora para a mudança. Para Nancy Cardoso Pereira (2003, p. 196), "experiência é entendida como uma operação interna - expressão do ser ou da consciência -, projeta uma subjetividade na forma de identidade essencial, de caráter universal, acessível a todos/as”. Portanto, a experiência é desenvolvida na vida cotidiana de mulheres, é parte da subjetividade de cada um/uma. E essa experiência será base para a epistemologia feminista, na visão de Wanda Deifelt (2002). Podemos conceber a experiência como base, haja vista que o conhecimento feminista é forjado, dentre outros elementos, no bojo da experiência. Evidentemente, trata-se de um conhecimento marginalizado durante séculos, pois o conhecimento das mulheres, devido à sua exclusão do mundo público, foi tecido em espaços privados.

Durante as orientações, a experiência de vida e os saberes adquiridos em outros espaços de educação foram elementos pontencializadores para a escrita, principalmente porque o movimento de politizar o privado (contribuição contundente do Feminismo) e a compreensão de que não existe saberes maiores nem menores (contribuição contundente da Educação Popular) auxiliaram, didaticamente, no difícil caminho do exercício da escrita acadêmica. E o resultado foi encantador. Por fim, retomo o pensamento de Paulo Freire: "movo-me na esperança enquanto luto e, se luto com esperança espero" (FREIRE, 2003, p. 69).

O meu desejo é que este relato de experiência ajude-nos na luta com esperança e que o grito da Via Campesina componha nosso cotidiano: Que se globalize a esperança! Sigamos!

\section{REFERENCIAS}

AGUIAR, Neuma. Patriarcado, sociedade e patrimonialismo. Sociedade e Estado. Brasília, v.15, n. 2, jun/dez. 2000.

BEAUVOIR, Simone. O segundo sexo. Rio de Janeiro: Nova Fronteira, 2009.

BRANDÃO, Carlos Rodrigues. O que é educação. São Paulo: Brasiliense, 2007.

CALDART, Roseli Salete. Educação do Campo. In: CALDART, Roseli Salete; 
PEREIRA, Isabel Brasil; ALENTEJANO, Paulo; FRIGOTTO, Gaudêncio. (org.). Dicionário da Educação do Campo. São Paulo: Expressão Popular, 2012.

CALDART, Roseli Salete; FETZNER, Andréa Rosana; FREITAS, Luiz Carlos de. Caminhos para transformação da Escola. São Paulo: Expressão Popular, 2015.

CANUDO, Antônio. Comissão Pastoral da Terra. In: CALDART, Roseli Salete; PEREIRA, Isabel Brasil; ALENTEJANO, Paulo; FRIGOTTO, Gaudêncio. (org.). Dicionário da Educação do Campo. São Paulo: Expressão Popular, 2012.

DEIFET, Vanda. O corpo e o cosmo. In: TIBIRI, Marcia; MENEZES, Magali M. de; EGGERT, Elle. As mulheres e a filosofia. São Leopoldo: UNISINOS, 2002.

FREIRE, Paulo. Pedagogia da autonomia: saberes necessários à prática educativa. São Paulo: Paz e Terra, 1999.

FREIRE, Paulo. Pedagogia da Esperança: Um reencontro com a Pedagogia do oprimido. São Paulo: Paz e Terra, 2003.

GEBARA, Ivone. O que é teologia feminista. São Paulo: Brasiliense, 2007.

HIERRO, Graciella. De la domesticación a la educación de las Mexicanas. Torres Asociados, 2007.

HIERRO, Graciella. Ética de la Libertad. Cidade do México: Torres Asociados, 2003.

LAGARDE, Marcela. Cautiverios de las mujeres: madresposas, monjas, putas, presas y locas. 4. ed. Ciudaddel México: UNAM, 2011.

LAGARDE, Marcela. El feminismo en mi vida. Hitos, claves y topías. Ciudade del Mexico: Govierno del Distrito Federal, 2012.

LAMAS, Marta. Cuerpo: diferencia sexual y género. Ciudade del Mexico: Taurus, 2002.

NEUENFELDT, Eliane. Práticas e experiências religiosas de mulheres no Antigo Testamento: considerações metodológicas. Disponível em: http://www3.est.edu.br/publicacoes/estudos_teologicos/vol4601_2006/et20061f_eneuenfeldt.pdf. Acesso em: 12 out. 2012.

NUSSBAUM, Martha. Las mujeres y el desarrollo humano. Barcelona. Herder. 2000 .

PALUDO, Conceição. Educação Popular. In: STRECK, Danilo; REDIN, Euclides; ZITKOSKI, Jaime José. (org.). Dicionário Paulo Freire. Belo Horizonte: Autêntica, 2008.

PALUDO, Conceição. Educação Popular. Educação Popular. In: CALDART, Roseli Salete; PEREIRA, Isabel Brasil; ALENTEJANO, Paulo; FRIGOTTO, Gaudêncio. 
(org.). Dicionário da Educação do Campo. São Paulo: Expressão Popular, 2012.

PEREIRA, Nancy Cardoso. Fragmentos e Cacos de Experiência1- Relações sociais de poder e gênero na teologia wesleyana. Revista Caminhando, São Paulo, v. 8, n. 2 , 2003.

PISANO, Margarita. El triunfo de la masculinidad. Fen-e-libros, 2004. Disponível em: http://webs.uvigo.es/pmayobre/pdf/pisano.pdf. Acesso em: 12 mar. 2012.

SAFFIOTI, Heleieth. I. B. Gênero e patriarcado. In: VENTURI, Gustavo; RECAMÁN, Marisol; OLIVEIRA, Suely de. A mulher brasileira nos espaços públicos e privados. São Paulo: Fundação Perseu Abramo, 2004.

SOUZA. Sandra Duarte de. A casa, as mulheres e a igreja: Gênero e a religião no contexto familiar. São Paulo: Fonte Editorial, 2009. 